\title{
Variabilidade climática e seus efeitos no processo de arenização em Gilbués-Piauí
}

\author{
Climate variability and its effects on sandization process in Gilbués-Piauí \\ SILVA $^{1}$, I. A. S.; BARROS ${ }^{2}$, J. R.; SUERTEGARAY ${ }^{3}$, D. M. A \\ ivamauro@hotmail.com
}

\begin{abstract}
Resumo
Na região sudoeste do estado do Piauí existem áreas que demonstram fragilidade ambiental em relação às características climáticas. Pretende-se nesta pesquisa, identificar os efeitos da variabilidade climática no processo de arenização em Gilbués-Piauí. O trabalho foi elaborado a partir da revisão bibliográfica, coleta e análise de dados meteorológicos, elaboração de gráficos de precipitação e realização de trabalhos de campo. Como resultados, o artigo apresenta as seguintes investigações: a) o processo de arenização decorrente principalmente, da forte erosividade das chuvas locais e da erodibilidade dos solos; b) as chuvas "enérgicas" favorecem o escoamento hídrico e potencializa a formação de processos erosivos. O processo de arenização em Gilbués é complexo e se localiza em um ambiente frágil com condições climáticas bem dinâmicas e com alta variabilidade pluviométrica e ainda episódios excepcionais de precipitações.
\end{abstract}

Palavras-chave: Clima; Arenização; Gilbués

\begin{abstract}
In the southwest of the state of Piauí there are areas that demonstrate environmental fragility in relation to climate characteristics. It is intended in this research, identify the effects of climate variability in sandization process in Gilbués-Piauí. The work was drawn from the literature review, collection and analysis of meteorological data, graphing rainfall and conducting field work. As a result, the article presents the following investigations: a) the sandization process due mainly to the strong erosivity local rainfall and soil erodibility; b) the rains "energetic" favor the water flow and enhances the formation of erosion. The sandization process in Gilbués is complex and is located in a fragile environment with very dynamic weather conditions and with high rainfall variability and exceptional episodes of rainfall.
\end{abstract}

Keywords: Climate; Sandization; Gilbués

\section{INTRODUÇÃO}

A região de Gilbués é denominada oficialmente pelo Programa de Ação Nacional de Combate à Desertificação e Mitigação dos Efeitos da Seca como um dos "núcleos de desertificação" do nordeste brasileiro, sendo considerado o maior núcleo do país, com extensão de aproximadamente $6.131 \mathrm{~km}^{2}$ (BRASIL, 2004).

A classificação da região de Gilbués como Núcleo de Desertificação (VASCONCELOS SOBRINHO, 1978; FERREIRA et al. 1994) é contestada por Sales (1997), ao considerar a questão climática, onde os índices de aridez (IA) oscilam entre 0,86 e 0,96, permanecendo fora da zona adotada pela Convenção das Nações Unidas para o Combate à Desertificação.

Pela proposta da ONU as áreas preferencialmente sujeitas à desertificação teriam índices de aridez inferiores a 0,65 , portanto, a região de Gilbués está fora das zonas suscetíveis ao fenômeno, por apresentar valores/índice de aridez bem acima do valor de referência da ONU.

Além do índice de aridez, existem outras diferenças climáticas que distingue o núcleo de 
Gilbués com as demais áreas suscetíveis à desertificação (ASD) no nordeste brasileiro, tais como: regime pluvial, distribuição pluviométrica e disponibilidade hídrica. Conforme a revisão teórica, os núcleos de Irauçuba-CE, Cabrobó-PE, Seridó-RN apresentam clima semiárido, totais pluviométricos inferiores a $800 \mathrm{~mm} / \mathrm{ano}$, extensos períodos de estiagem e escassez de recursos hídricos.

O núcleo de Gilbués apresenta pluviosidade em torno de 1.200 mm/ano, ausência de aridez, carência de baixos índices pluviométricos, abundância hídrica (rios perenes e aquíferos) e tem predominância de um período chuvoso que se concentra entre os meses de outubro a maio, sendo bem distribuído para uma ASD (SILVA, 2014, p.173).

Segundo os conceitos apresentados pela literatura científica sobre o processo de desertificação e conforme as diferenças climáticas do núcleo de Gilbués com os demais considerou inadequado o emprego do termo desertificação. Assim, avaliou ser mais adequado, o emprego do conceito arenização, na tentativa de explicar a dinâmica do processo que ocorre na área em estudo.

Suertegaray (1992, p. 71) conceitua arenização como "o processo de retrabalhamento de depósitos arenosos pouco ou não consolidados, que promove, nessas áreas, uma dificuldade de fixação da cobertura vegetal, devido à intensa mobilidade de sedimentos arenosos pela ação das águas (erosão hídrica) e dos ventos (erosão eólica)".

Já o processo de desertificação, conforme Suertegaray (2001) é reservado para expressar a degradação do solo, vegetação e água em condições climáticas específicas, bem como períodos secos prolongados, baixos índices pluviométricos e presença de aridez.

Suertegaray (2001) elucida que a dinâmica dos processos envolvidos na arenização requer disponibilidade de água. Conforme Suertegaray (1992), a elevada precipitação, em particular aquela concentrada em chuvas torrenciais, favorece os processos de escoamento, potencializando a formação de ravinas e voçorocas, feições resultantes do escoamento hídrico.

Suertegaray (2006, p. 69) complementa que "a gênese do processo de arenização, está associado à formação de ravinas que evoluem para voçorocas e depositam a jusante, leques arenosos". Essas características integradas com a evolução das próprias voçorocas dão origem aos areais, impulsionados, também pelo escoamento superficial hídrico e dinâmica eólica (Figura 1). 


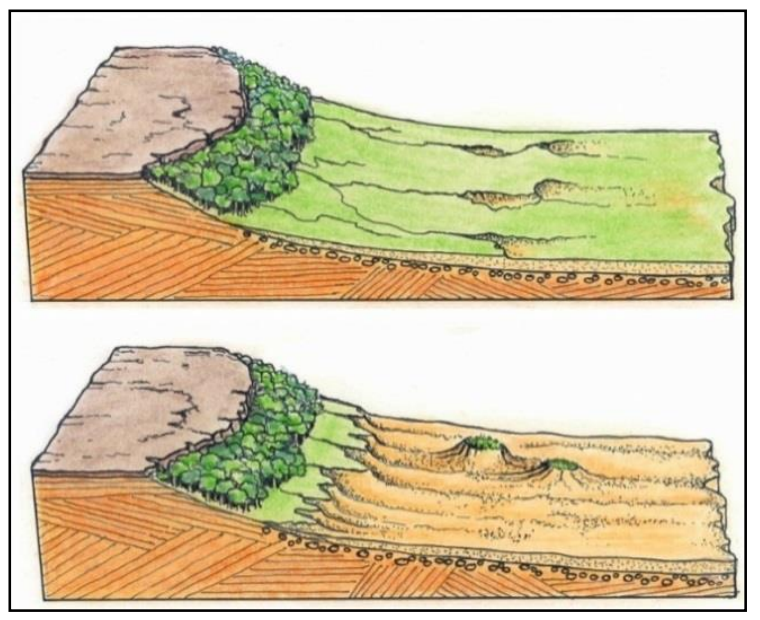

Figura 1 - Esquema de interpretação da gênese da arenização. Fonte: SUERTEGARAY, 2001

De acordo com Suertegaray (1992) o processo de arenização está restrito a regiões de clima úmido, embora períodos de estiagem sejam comuns, é um fenômeno que envolve erosão, transporte e acumulação. Verdum (1997) afirma que as precipitações elevadas são um motor do processo de arenização, pois atingem as formações superficiais com fragilidade estrutural, e a cobertura de campo pouco protetora. Essa fragilidade permite a formação de ravinas e voçorocas, que representam processos de escoamento retrabalhando os sedimentos, juntamente, com a ação eólica.

Pelo exposto, a análise do clima e, especificamente, a variabilidade pluviométrica que apresenta a área de estudo como, por exemplo, precipitação com alta variação espaço-temporal, com distribuição desigual no decorrer do ano, tanto em escala anual como mensal e diária merece destaque. Esse comportamento pluvial é de grande relevância para avaliar os riscos naturais que potencializam o processo de arenização.

Nesse sentido, a precipitação é uma das variáveis meteorológicas mais consideradas para os estudos climáticos. Tal importância reside em seu regime, quando sucede em um curto intervalo de tempo (chuva intensa), podem acarretar impactos adversos na paisagem.

Assim, as principais características físicas da chuva atuantes nos processos erosivos na paisagem são: a quantidade total, a intensidade e a distribuição (BERTONI e LOMBARDI NETO, 1985). Contudo, dentre as três características é fundamental se conhecer a intensidade, pois representa a relação entre as outras duas importantes características: quanto chove (quantitativo) e quando chove (temporal).

Neste contexto, a pesquisa tem como objetivo geral: investigar os efeitos do clima no processo de arenização em Gilbués, por meio do estudo da dinâmica pluviométrica. Como objetivos específicos vale elencar: a) elucidar a influência da pluviosidade no desencadeamento do processo de arenização; b) evidenciar os períodos que potencializam os processos erosivos e fluxos hídricos. 


\section{METODOLOGIA}

A pesquisa foi realizada em três etapas distintas e complementares. No primeiro momento, procedeu-se verificação bibliográfica sobre o tema, de onde foram extraídos os conceitos norteadores (clima e arenização); no segundo momento levantaram-se dados sobre o regime pluviométrico anual, mensal e diário, definidos conforme a excepcionalidade, a quantidade pluvial e episódios que oferecem risco para a paisagem.

Os dados pluviométricos foram obtidos pela Estação Hidroclimática da Superintendência do Desenvolvimento do Nordeste (SUDENE). Essa etapa possibilitou a elaboração dos pluviogramas (gráficos de precipitação) que equivale numa representação cartográfica que mostram a variação porcentual das precipitações mensais/diárias em relação à precipitação total de cada ano/mês, indicando o mês mais seco e o mês mais úmido e revelando, por meio de um histograma, os totais pluviométricos anuais e sua espacialização dos períodos estudados (1964, 1973, 1980, e 1983) definidos, principalmente pela quantidade pluvial e pelo comportamento excepcional. Por último foi realizado o trabalho de campo, com intuito de verificar os seguintes aspectos: a) análise empírica da paisagem; b) reconhecimento das unidades geoambientais; c) registros fotográficos.

\subsection{Caracterização da área de estudo: localização, aspectos geoambientais e socioeconômicos}

A área de estudo localiza-se em Gilbués, município situado no sudoeste do estado do Piauí (Figura 2). O sítio urbano foi fundado em 1938 e, segundo o Censo 2010 do IBGE, tem uma população total de 10.402 habitantes. A área de unidade territorial compreende um total de 3.495,18 $\mathrm{km}^{2}$, o que resulta numa densidade demográfica de 2,94 habitantes por $\mathrm{km}^{2}$. A sede municipal encontra-se a $742 \mathrm{~km}$ da capital Teresina.

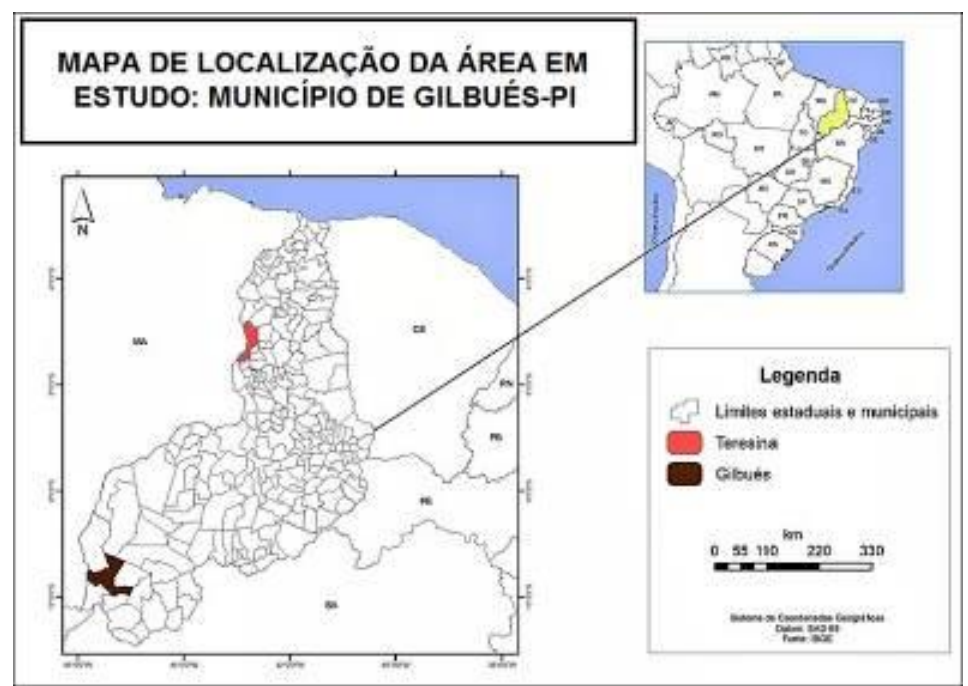

Figura 2 - Localização da área de estudo - munícipio de Gilbués 
A litologia da área em estudo apresenta terrenos sedimentares (Bacia do Parnaíba e São Francisco). Segundo Sales (2003) as características geológicas de Gilbués, destacam-se por apresentar litologias extremamente vulneráveis à erosão, representadas basicamente por siltitos, arenitos, argilitos, calcário e conglomerados distintos. Os principais tipos de solos são: Latossolo Amarelo, Argissolo vermelho-amarelo, Neossolo Quartzarênico e Neossolo litólico.

As chapadas, chapadões, feições residuais de morros, morros testemunhos, morrotes com topos planos e encostas escarpadas e compartimentos dissecados são as feições geomorfológicas predominantes. Tem altimetria que varia entre 297 metros (vale do Rio Gurguéia) a 665 metros de altitude (chapadas do Uruçuí). A rede hidrográfica está representada pelos altos cursos dos rios Parnaíba, Uruçuí Vermelho, Uruçuí Preto e Gurguéia, com drenagem relativamente densa e perene, além de outros corpos hídricos de regime intermitente: riachos Boqueirão, Santa Maria, Cavalos, Urucuzal, Marmelada e Sucuruiu (SILVA, p. 81, 2014).

Quanto à cobertura vegetal, há predomínio de diferentes características fitofisionômicas de Cerrado (Cerradão, Campo Sujo e Limpo, Sensu Stricto, Campo Cerrado, Mata Galeria e Veredas). Conforme classificação de Köppen, o clima predominante é o semiúmido (Tropical chuvoso com seca no inverno) com 4 a 5 meses de estiagem. A pluviosidade média anual é definida no regime tropical continental, apresentando, segundo Silva (2014) totais pluviométricos em torno de 1.200 $\mathrm{mm}$, se caracterizando por uma ampla variação e excepcionalidades no regime e ritmo das chuvas. Esse índice pluviométrico concentra-se entre os meses de outubro a maio.

No que se refere ao uso e ocupação das terras as principais atividades desenvolvidas atualmente, segundo Silva (2014) é a pecuária (semi-intensiva e extensiva) e lavouras temporárias e permanentes de grãos (feijão, mandioca, arroz, milho e soja).

\section{RESULTADOS E DISCUSSÃO}

Nesta pesquisa foram analisados a pluviosidade mensal dos anos de 1964, 1973, 1980, e 1983 (Figura 3) e na forma diária, considerando os meses que apresentaram maior quantidade pluviométrica e excepcionalidades, ou seja, episódios que oferecem riscos a paisagem (janeiro, fevereiro e março), bem como o período da transição climática (inverno-primavera) representados pelos meses de setembro (S) e outubro $(\mathrm{O})$. 

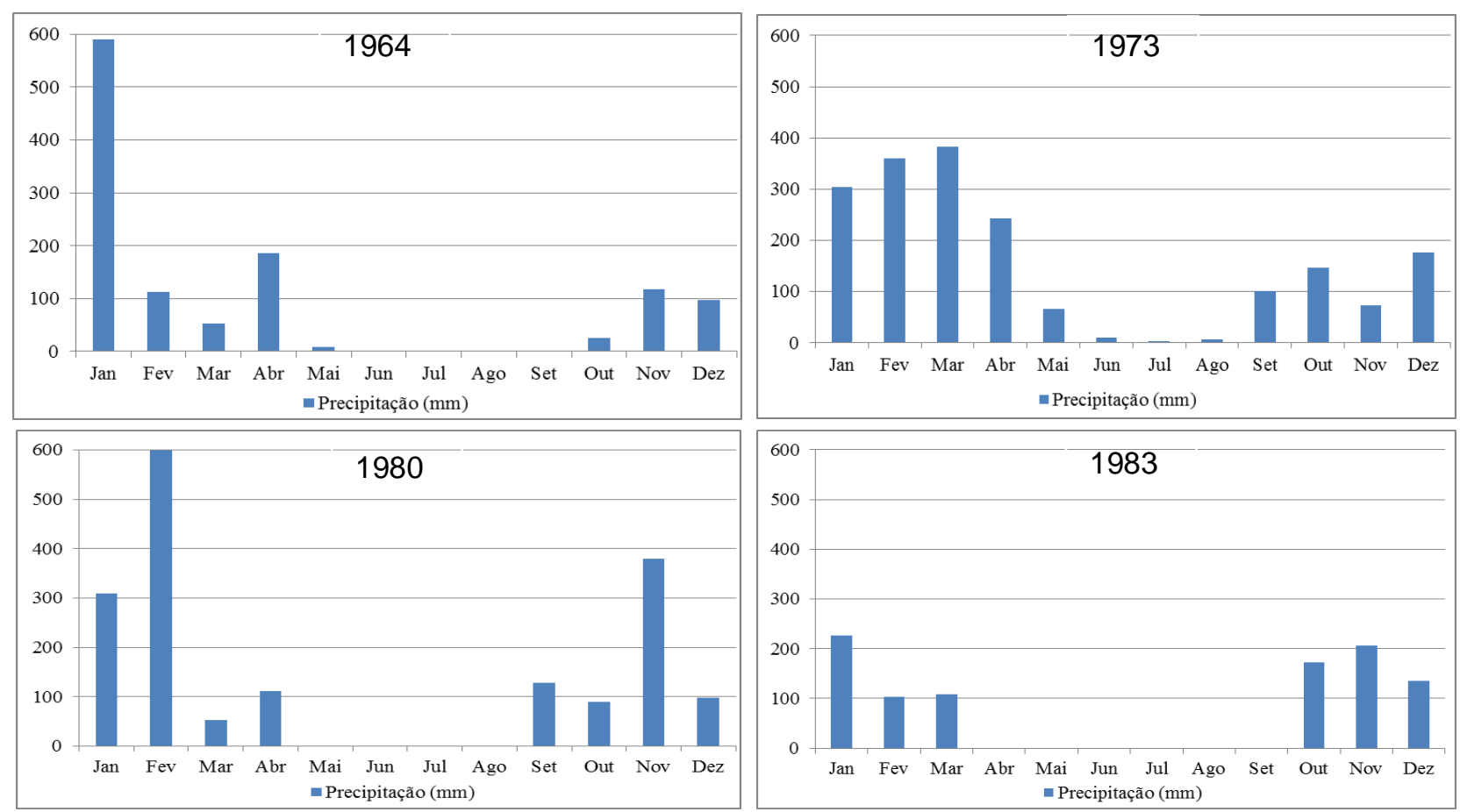

Figura 3 - Gráficos de precipitação mensal (1964, 1973, 1980 e 1983) - Gilbués-Piauí. Fonte: SUDENE Elaboração: Ivamauro Ailton de Sousa Silva.

Em 1964 os totais pluviométricos atingiram $1.190 \mathrm{~mm}$ e a distribuição da chuva teve um comportamento excepcional, no qual, se observa episódios pluviométricos concentrados no mês de janeiro e já em outros meses a ocorrência pluviométrica foi desigual.

No ano de 1973, o regime pluviométrico atingiu totais de $1.867 \mathrm{~mm}$, foi um ano atípico, pois o volume pluvial apresentou excepcionalidade, as chuvas, por exemplo, foram distribuídas entre setembro-maio e com baixos volumes em junho e agosto.

Já em 1980, verificou-se a existência de variabilidade no regime pluviométrico e também variação no ritmo (distribuição) pluviométrico. Nesse período, os totais atingiram $1.717 \mathrm{~mm}$, o volume de chuva se acumulou em janeiro, fevereiro e novembro. O ano de 1983 apresentou totais pluviométricos de $951 \mathrm{~mm}$, assim a dinâmica pluviométrica foi caracterizada por regime com padrão seco. A estiagem durou 6 meses e as chuvas iniciaram em outubro com quantidades elevadas.

Os detalhes no tocante ao quadro pluviométrico, bem como a distribuição diária das chuvas nos períodos analisados, são verificados diretamente em cada um dos pluviogramas apresentados a seguir (Figura 4). A sequência dos gráficos corresponde à análise diária, aplicando ênfase aos eventos pluviais com excepcionalidade e meses/episódios com maior volume de chuva. 

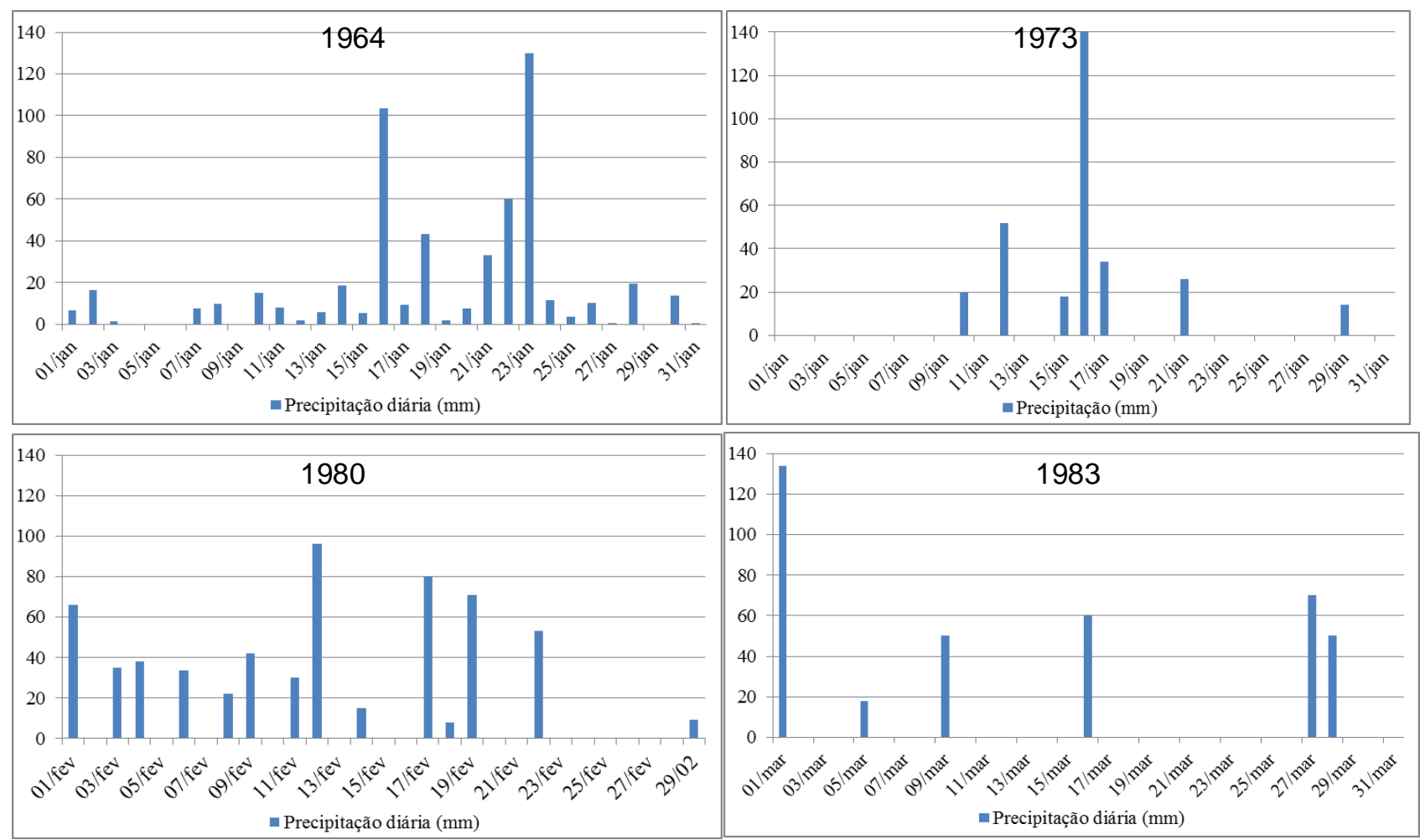

Figura 4 - Gráficos de precipitação diária - meses de janeiro, fevereiro e março. Fonte: SUDENE Elaboração: Ivamauro Ailton de Sousa Silva

A partir da análise diária representada na figura 4, nota-se que os meses de janeiro (1964 e 1973) e março (1983) apresentaram excepcionalidades no regime e ritmo pluviométrico, destacando a ocorrência de dias com volumes de chuva entre $60 \mathrm{~mm}$ a $140 \mathrm{~mm}$. Essa quantidade é capaz de alterar as características geoambientais e também potencializar os processos erosivos. O mês de fevereiro (1980) registrou dias com elevados volumes de precipitação e ainda revelou uma boa frequência pluviométrica, havendo dias com quantidades de chuvas moderadas variando de $2 \mathrm{~mm}$ a 41 mm. Em março de 1983, os dias apresentaram episódios fracos e moderados de chuvas intercalados com períodos de estiagem. Houve também eventos com precipitação elevada que atingiram quantidades entre $60 \mathrm{~mm}$ a $135 \mathrm{~mm}$.

Detalhando um pouco mais a descrição do quadro pluviométrico, convém mencionar outros episódios considerados "críticos" que ocorre na época da transição climática (fim da estiagem e inicio das chuvas), no qual, as primeiras chuvas ocorrem de forma "enérgica" com volumes que apresentam uma variabilidade entre dias elevados e moderados de precipitação (Figura 5) que aumentam a vulnerabilidade da paisagem aos processos erosivos do solo. 

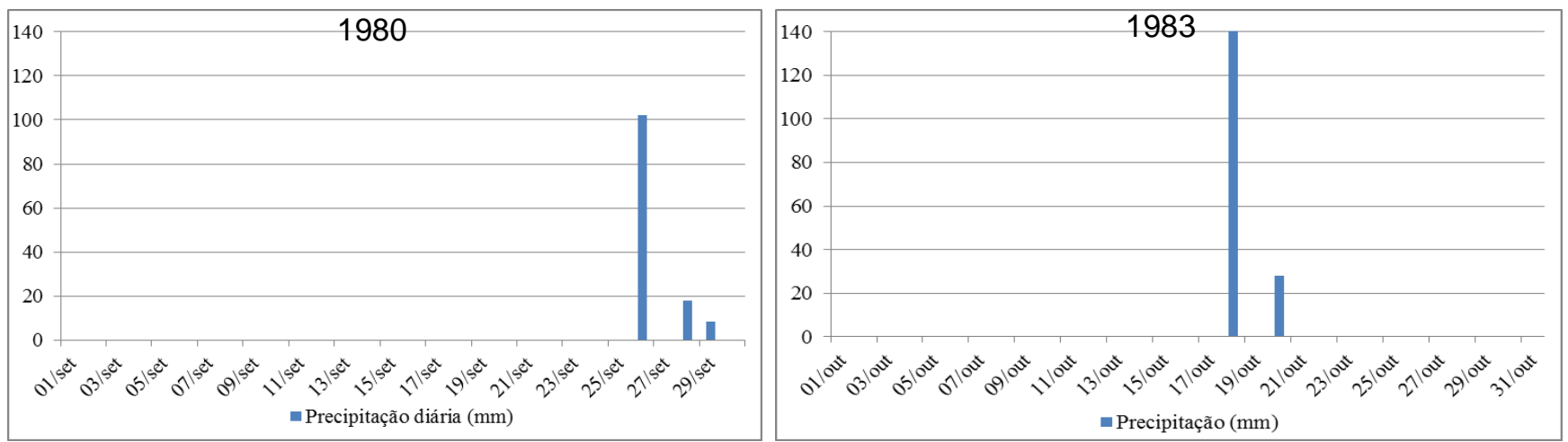

Figura 5 - Gráficos de precipitação diária - setembro e outubro. Fonte: SUDENE

Elaboração: Ivamauro Ailton de Sousa Silva

Durante o período da chamada "transição climática", nota-se que os episódios de chuva atingiram volumes elevados de precipitação. Na estiagem, a intensa radiação solar com consequentes altas temperaturas, alteram as características ambientais da paisagem deixando principalmente o solo e vegetação ressecada. Portanto, trata-se de uma época em que a vegetação composta por arvores anãs, gramíneas e herbáceas está degradada e não oferece proteção ao solo que se encontra seco (Figura 6). Para esse período, quantidades elevadas de chuva potencializam os processos de escoamento superficial em função das características geomorfológicas (comprimento da rampa) acelerando a dinâmica dos processos erosivos no solo.

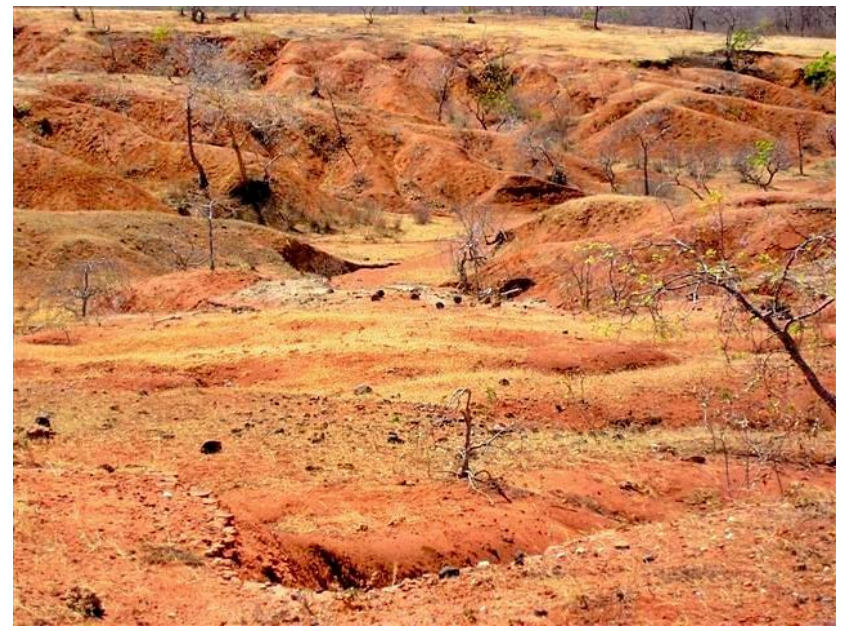

Figura 6 - paisagem de Gilbués no período da seca (agosto). Fonte: Ivamauro Ailton de Sousa Silva

Nesse sentido, se pode afirmar que, durante o fim da estiagem, as "primeiras" chuvas acarretam transformações na paisagem e potencializam os processos de escoamento superficial, pois em condições de suscetibilidade (solo ressecado, vegetação degradada, rampas longas), a ocorrência de episódios intensos de chuva, a paisagem, consequentemente não consegue oferecer sustentação/equilíbrio, tornando-se vulnerável aos eventos pluviométricos intenso-concentrados, 
pois se trata de características pluviométricas (quantidade/volume) superior a capacidade de suporte do ambiente.

Na estação chuvosa, a erosão hídrica predomina na região, sendo responsável pela presença de águas barrentas, resultado de chuvas concentradas que arrastam e depositam enorme quantidade de sedimentos em áreas rebaixadas, transportados pelo escoamento superficial e fluxos hídricos devido às rampas longas (Figura 7).

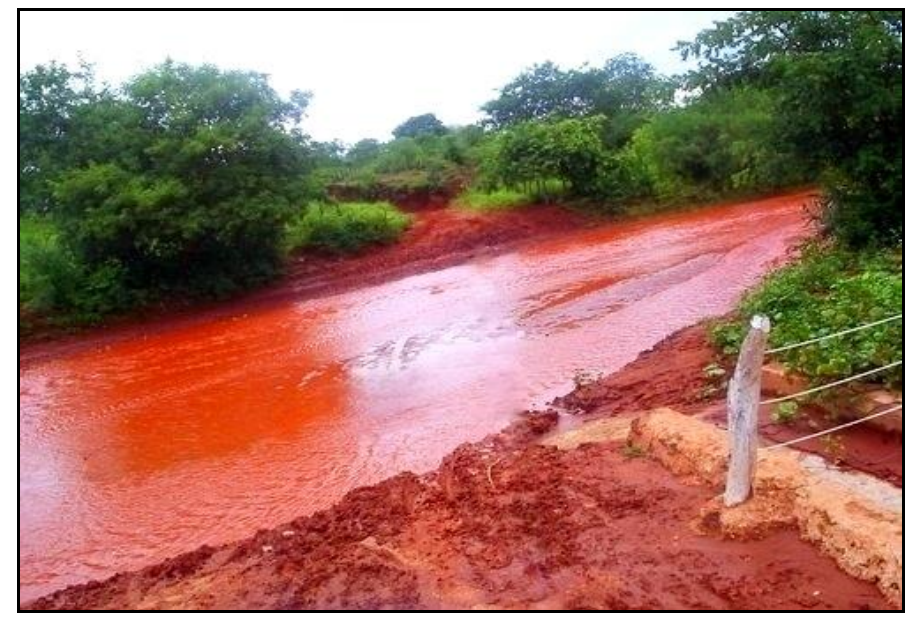

Figura 7 - Erosão hídrica e presença de águas barrentas na zona rural de Gilbués. Fonte: SILVA, 2014

Diante do panorama apresentado, e notório reconhecer a fragilidade da paisagem associada com a dinâmica climática que se caracteriza pela presença de eventos chuvosos concentrados. Essas características potencializam os fluxos hídricos e processos superficiais no solo, ocasionando a gênese de processos erosivos no solo e consequentemente a arenização.

\section{CONSIDERAÇÕES FINAIS}

A obtenção dos dados e análise diária dos meses de maior intensidade pluviométrica e dos meses que situam no fim da estiagem e inicio das chuvas, permitiu identificar a presença de eventos extremos e compreender a variabilidade pluviométrica, demostrando os seguintes comportamentos: a) distribuição pluviométrica irregular, havendo concentração de chuva num episódio prolongando e dias com ausência de chuva num período curto ou prolongado;

b) ocorrência de chuvas concentradas e frequentes em um só período intercaladas com episódios de estiagem;

c) dias com chuva intensa intercalados com episódios de baixa quantidade pluviométrica;

d) vários dias com chuva "enérgica" acima de $80 \mathrm{~mm}$ e também episódios diários de chuva que atingiram volume de $144 \mathrm{~mm}$;

e) as primeiras chuvas, após o período da seca são extremamente enérgicas. 
O clima, principalmente no que se refere à variabilidade e irregularidade das chuvas, assume um papel extraordinariamente decisivo no entendimento da erosividade. Desta forma, o estudo sobre a influência das chuvas, continua a merecer maiores e melhores análises climatológicas, destacando a aplicação dos conceitos de climatologia dinâmica, enfocando o papel da chuva na ocorrência do fenômeno da erosão e demais formas de degradação dos solos (arenização e desertificação).

O processo de arenização em Gilbués é complexo e se localiza em um ambiente frágil com condições climáticas bem dinâmicas com alta variabilidade pluviométrica. Sob essas condições, a paisagem se modifica mais rapidamente, alterando as formas das vertentes, tornando os processos morfogéneticos e morfodinâmicos mais intensos. Esses processos atuam concomitantemente dependendo das condições climáticas e morfopedológicas.

A análise do clima como fenômeno geográfico indica uma concepção teórica em que, além dos estudos físicos dos elementos meteorológicos, permite interações com os processos que ocorrem na paisagem, por meio de uma análise integrada, considerando as potencialidades, limitações e vulnerabilidades do ambiente.

\section{REFERÊNCIAS}

BERTONI, J.; LOMBARDI NETO, F. Conservação dos solos. Piracicaba: Livroceres, 1985

BRASIL. Programa de ação nacional de combate à desertificação e mitigação dos efeitos da seca-PAN-Brasil. Brasília, DF: Ministério do Meio Ambiente. Secretaria de Recursos Hídricos, 2004. 242p.

FERREIRA, D. G.; MELO, H. P.; RODRIGUES NETO, F. R.; NASCIMENTO, P. J. S.; RODRIGUES, V. Avaliação do Quadro da Desertificação no Nordeste do Brasil: Diagnósticos e Perspectivas. Anais da Conferencia Nacional da Desertificação, Fortaleza. Brasília, Fundação Grupo Esquel Brasil, 1994. p. 7-55.

INSTITUTO BRASILEIRO DE GEOGRAFIA E ESTATÍSTICA - IBGE. Censo Demográfico de 2010 - município de Gilbués. Rio de Janeiro, IBGE.

SALES, M. C. L. Estudo da degradação ambiental em Gilbués-PI: Reavaliando o "núcleo de desertificação". São Paulo, USP. Dissertação de Mestrado apresentada ao Programa de PósGraduação em Geografia Física da Universidade de São Paulo, 1997. 181p.

SALES, M. C. L. Degradação Ambiental em Gilbués, Piauí. Revista Mercator. Fortaleza, 02, 04, 2003. p.115-124

SILVA, I. A. S. Clima e arenização em Gilbués-Piauí: dinâmica das precipitações e a vulnerabilidade da paisagem aos eventos pluviais intensos. Dissertação de Mestrado apresentada ao Programa de Pós-graduação em Geografia da Universidade Federal de Goiás: Goiânia, 2014. 185 p. 
SUPERINTENDENCIA DE DESENVOLVIMENTO DO NORDESTE - SUDENE. Rede Hidroclimatológica do Nordeste. Estação de Gilbués-Piauí.

SUERTEGARAY, D. M. A. Deserto Grande do Sul: Controvérsia. Porto Alegre: Editora da Universidade, UFRGS, 1992.

SUERTEGARAY, D. M. A.; GUASSElli, L. A. e VERDUM, R. (Org.) Atlas da arenização Sudoeste do Rio Grande do Sul. Porto Alegre/RS: Secretaria da Coordenação e Planejamento, $2001.85 \mathrm{p}$.

SUERTEGARAY, D. M. A. Desertificação: recuperação e desenvolvimento sustentável. In: GUERRA, A. J. T.; CUNHA, S. B (Org.). Geomorfologia e Meio Ambiente. $6^{\text {a }}$ ed. Rio de Janeiro: Bertrand Brasil, 2006

VASCONCELOS SOBRINHO, J. Metodologia para identificação dos processos de desertificação: manual de indicadores. Recife, SUDENE. 18p. 1978

VERDUM, R. Approche géographique des deserts dans lês communes de São Francisco de Assis et Manuel Viana - Etat do Rio Grande do Sul. 211f. Tese de Doutorado em Geografia apresentada na Université de Toulouse II (Le Mirai), U.T.H, França. 1997.

\section{AGRADECIMENTO}

Os autores agradecem a Coordenação de Aperfeiçoamento de Pessoal de Nível Superior (CAPES) pela atual concessão de bolsa no Doutorado na Universidade Federal do Rio Grande do Sul.

Recebido em: 14/08/2016

Aceito para publicação em: 01/10/2016 